\title{
Discontinuity in the Realization of the Vienna Peedee Belemnite Carbon Isotope Ratio Scale
}

\author{
Jean-François Hélie,* Agnieszka Adamowicz-Walczak, Paul Middlestead, Michelle M.G. Chartrand, \\ Zoltán Mester, and Juris Meija
}

Cite This: Anal. Chem. 2021, 93, 10740-10743

Read Online

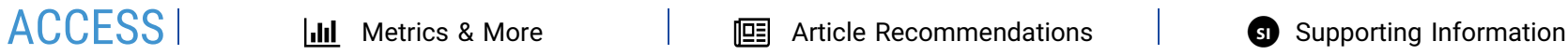

ABSTRACT: By convention, carbon isotope ratios are expressed relative to VPDB defined by the calcite standard NBS19 in the 1980s. [See T. Coplen, Pure Appl. Chem. 1994, 66, 273-276.] To improve the realization of the VPDB scale, a second fixed point (lithium carbonate, LSVEC) was introduced in 2006 [T. Coplen et al. Anal. Chem. 2006, 78, 2439-2441], which is now known to be isotopically unstable. [Assonov, S. Rapid Commun. Mass Spectrom., 2018, 32, 827-830.] With the high-quality reference materials made available in 2020, it is now possible to realize the VPDB scale with high confidence. [Assonov, S. et al. Rapid Commun. Mass Spectrom., 2020, 34, e8867; Assonov, S. Rapid Commun. Mass Spectrom. 2021, 35, e9014; Qi, H. et al. Rapid Commun. Mass

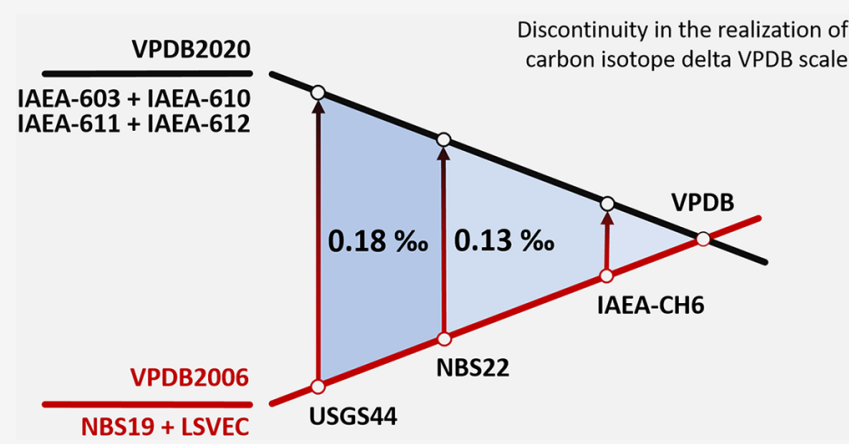
Spectrosc. 2021, 35, e9006.] Here, we report the analysis of 25 reference materials using isotope ratio combustion mass spectrometry, show the discontinuity between the values measured against the new IAEA reference materials and the values currently assigned to these reference materials on the VPDB2006, and provide a link bringing these materials onto the new VPDB2020.

$\mathrm{C}$ arbonate reference materials have long been used as standards for reporting natural variations of carbon isotope ratios. Since the 1980 s, the zero point of this scale is, by convention, a virtual material (Vienna PeeDee Belemnite, VPDB), defined by a fixed isotope ratio value assigned to a calcite reference material NBS19. ${ }^{1}$ Efforts are underway to provide SI-traceable isotopic composition of carbon for this material. ${ }^{7,8}$ While there is a general desire in metrology to define reliable measurement units and scales that do not rely on physical artifacts, physical standards are often employed to disseminate such scales. In this sense, the relative carbon isotope ratio (isotope delta) scale is similar to temperature measurements: both have scale-defining zero points (absolute zero and VPDB) and practical realization of both scales typically relies on a constellation of calibration standards, as exemplified with the ITS-90 temperature scale. ${ }^{9}$

The carbon isotope delta scale is defined by a single fixed point. To improve agreement between different laboratories, however, a second fixed-point reference material on which to normalize carbon isotope delta values has been widely desired, ${ }^{10}$ largely to account for instrumental effects. ${ }^{11}$ However, the isotopic instability of the second fixed-point (LSVEC), coupled with the limited access to NBS19, have challenged the reliability of carbon isotope ratio measurements and have led to renewed efforts toward a more reliable realization of the VPDB isotope ratio scale. ${ }^{12}$ Indeed, maintaining the long-term stability of carbon isotope measurements means not only reducing offsets between laboratories from calibration but also aims at improving the consistency of values assigned to the reference materials themselves. ${ }^{13}$

The recent introduction of new carbonate reference materials $^{4,5}$ now allows two different realizations of the VPDB scale. One can either continue to employ the existing reference materials, which were characterized with NBS19 and LSVEC as fixed points (the VPDB2006 scale realization) or use the new set of reference carbonates IAEA-603, IAEA-610, IAEA-611, and IAEA-612 (the VPDB2020 scale realization). Here, we compare these two VPDB scale realization approaches using isotope ratio mass spectrometry by analyzing certified reference materials. The systematic offset between the isotope delta values assigned to these materials (on the VPDB2006) and those measured on the VPDB2020 is shown in Figure 1. Our results show that isotope delta values currently assigned to carbon reference materials, and subsequently to all measurements that rely on them, are biased. This bias varies linearly and reaches $+0.20 \%$ in the vicinity of natural methane, well above the World Meteorological Organization (WMO) data quality objective of $\pm 0.02 \%$. We also analyzed

Received: June 10, 2021

Accepted: July 21, 2021

Published: July 27, 2021 


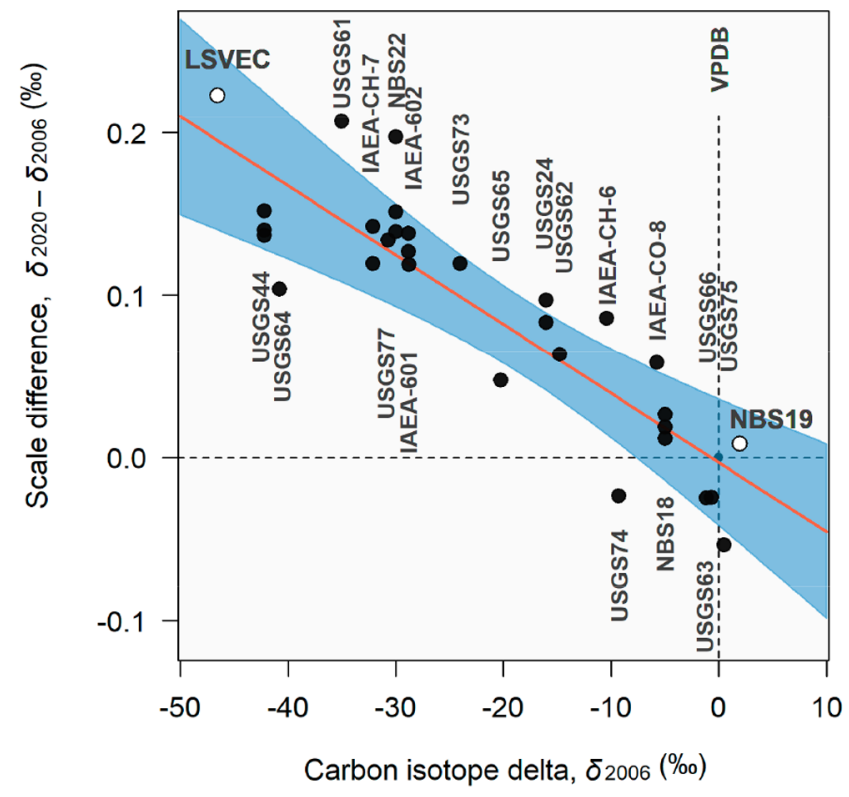

Figure 1. Carbon isotope delta measurements of 19 reference materials (solid circles), NBS19 and LSVEC (open circles), against the IAEA 603-610-611-612 reference materials (VPDB2020) show systematic bias (difference) from the values currently assigned to them (VPDB2006), a consequence of using LSVEC as the second fixed point in VPDB2006. Neither LSVEC nor NBS19 were used to obtain the red line. Blue area represents the $95 \%$ credible interval for the bias between the two VPDB scale realizations with due account for the uncertainties assigned to all reference materials. Each black dot is the average measurement result from one of the seven measurement sequences performed over the span of one year.

samples of LSVEC and NBS19 whose average results, shown in Figure 1, align well with the trend observed from all other reference materials. This bias trend (the red line) can be used to adjust the isotope delta values currently assigned to reference materials using the NBS19-LSVEC scale realization (VPDB2006) to bring them on the new VPDB2020. For example, the value currently assigned to the NBS22 reference oil, $\delta_{\mathrm{VPDB} 2006}=-30.03 \%$ corresponds to a bias of $+0.13 \%$, meaning that the isotope delta value of NBS22, relative to the $\mathrm{VPDB}$, ought to be $\delta_{\mathrm{VPDB} 2020}=-30.03 \%$ oo $0.13 \%$ o $=$ $-29.90 \%$ o (see Table 1 ).

The problems with isotopically unstable LSVEC standard ${ }^{3}$ illustrate that our incomplete understanding of the absolute isotopic composition of VPDB is only a part of the overall struggle for making more trustworthy measurements. Carbon isotope analysis of the NBS22 reference oil over the last four decades, shown in Figure 2, captures the scale of uncertainties inherent with the realization of the VPDB scale and our results for NBS22, shown with a black hollow circle, agree well with the latest data before the introduction of LSVEC as a second fixed point. Recently, USGS44 $\mathrm{CaCO}_{3}$ reference material has been proposed as a suitable replacement for LSVEC. ${ }^{6}$ The preferred value for this material using a single anchor (NBS19), -42.08(1)\%o, ${ }^{6}$ agrees well with our measurements against the suite of four International Atomic Energy Agency (IAEA) reference materials, $-42.07(2) \%$, and instills further confidence of its isotopic composition relative to the VPDB. Together, these findings lend further confidence to adopt the VPDB scale realization based on IAEA reference materials 603-610-611-612. Questions in the realization of the VPDB
Table 1. Carbon Isotope Delta Values for Certified Reference Materials Analyzed in This Study

\begin{tabular}{|c|c|c|c|}
\hline \multirow[b]{2}{*}{$\begin{array}{l}\text { reference } \\
\text { material }\end{array}$} & \multicolumn{3}{|c|}{ Carbon Isotope Delta Values (\%o) } \\
\hline & $\begin{array}{c}\text { measured value }{ }^{a}, \\
\delta_{\mathrm{VPDB} 2020}\left({ }^{13} \mathrm{C}\right)\end{array}$ & $\begin{array}{l}\text { certified value }{ }^{b}, \\
\delta_{\text {VPDB2006 }}\left({ }^{13} \mathrm{C}\right)\end{array}$ & $\begin{array}{l}\text { bias-corrected certified } \\
\text { value }^{c}, \delta_{\text {VPDB2020 }}\left({ }^{13} \mathrm{C}\right)\end{array}$ \\
\hline LSVEC & $-46.38(2)$ & -46.6 (exact) & $-46.40(3)$ \\
\hline USGS44 & $-42.07(2)$ & $-42.21(5)$ & $-42.03(6)$ \\
\hline USGS64 & $-40.71(4)$ & $-40.81(4)$ & $-40.64(5)$ \\
\hline USGS61 & $-34.84(2)$ & $-35.05(4)$ & $-34.90(4)$ \\
\hline $\begin{array}{l}\text { IAEA- } \\
\text { CH-7 }\end{array}$ & $-32.02(2)$ & $-32.15(5)$ & $-32.02(5)$ \\
\hline USGS77 & $-30.58(2)$ & $-30.71(4)$ & $-30.58(4)$ \\
\hline NBS22 & $-29.87(2)$ & $-30.03(5)$ & $-29.90(5)$ \\
\hline IAEA-602 & $-28.72(1)$ & $-28.85(4)$ & $-28.73(4)$ \\
\hline IAEA-601 & $-28.69(2)$ & $-28.81(4)$ & $-28.69(4)$ \\
\hline USGS73 & $-23.91(3)$ & $-24.03(4)$ & $-23.93(4)$ \\
\hline USGS65 & $-20.24(1)$ & $-20.29(4)$ & $-20.21(4)$ \\
\hline USGS24 & $-15.96(1)$ & $-16.05(4)$ & $-15.98(4)$ \\
\hline USGS62 & $-14.73(1)$ & $-14.79(4)$ & $-14.73(4)$ \\
\hline $\begin{array}{l}\text { IAEA- } \\
\text { CH-6 }\end{array}$ & $-10.36(2)$ & $-10.45(4)$ & $-10.41(4)$ \\
\hline USGS74 & $-9.32(3)$ & $-9.30(4)$ & $-9.26(4)$ \\
\hline $\begin{array}{l}\text { IAEA- } \\
\text { CO-8 }\end{array}$ & $-5.71(2)$ & $-5.764(32)$ & $-5.74(4)$ \\
\hline NBS18 & $-4.99(1)$ & $-5.014(35)$ & $-5.00(4)$ \\
\hline USGS63 & $-1.19(3)$ & $-1.17(4)$ & $-1.17(4)$ \\
\hline USGS66 & $-0.69(2)$ & $-0.67(4)$ & $-0.67(4)$ \\
\hline USGS75 & $+0.44(3)$ & $+0.49(7)$ & $+0.48(7)$ \\
\hline NBS19 & $+1.96(2)$ & $+1.95($ exact $)$ & \\
\hline
\end{tabular}

${ }^{a}$ Measured average values and their standard uncertainties, using VPDB2020 scale realization. ${ }^{b}$ Certified values currently assigned to the reference materials, using VPDB2006 scale realization. ${ }^{c}$ Biascorrected certified values calculated using the bias function shown in Figure $1, \delta_{\mathrm{VPDB} 2020}\left({ }^{13} \mathrm{C}\right)=a+(1+b) * \delta_{\mathrm{VPDB} 2006}\left({ }^{13} \mathrm{C}\right)$ with coefficients $a=-0.003$ and $b=-0.0043$ when results are expressed in permilles, their standard uncertainties $u(a)=0.020$ and $u(b)=$ 0.0009 and correlation $r(a, b)=0.8$.

scale still persist, most notably regarding the inhomogeneity of the NBS19 material itself, likely to be $\pm 0.01 \% 0^{12}$ and not zero as defined.

Our results show a systematic bias in international carbon isotope reference materials, which have been characterized using the NBS19 and LSVEC normalization (VPDB2006). With the VPDB2020 scale realization, ${ }^{12}$ our measurements of international reference materials (black points in Figure 1) suggest the value of LSVEC is -46.40 (3)\%o and not $-46.6 \%$, relative to the VPDB. This finding confirms a similar hypothesis recently put forward based on discrepancies observed from measurements of USGS44. ${ }^{6}$ Thus, it is evident that the introduction of LSVEC as a second anchor in 2006 has led to a systematic bias in carbon isotope delta measurements, which can be reconciled retroactively, using a linear transformation $\delta_{\mathrm{VPDB} 2020}\left({ }^{13} \mathrm{C}\right)=a+b \delta_{\mathrm{VPDB} 2006}\left({ }^{13} \mathrm{C}\right)$ with coefficients $a=-0.003$ and $b=-0.0043$ when results are expressed in permilles, their standard uncertainties $u(a)=$ 0.020 and $u(b)=0.0009$ and correlation $r(a, b)=0.8$.

Our work demonstrates that one can provide carbon isotope delta results with uncertainties near $0.02 \%$ when measured using the suite of IAEA 603-610-611-612 reference materials (Table $S 1$ in the Supporting Information) and we do believe that this VPDB scale realization approach, as presented by Assonov et al., ${ }^{4,5}$ will lead to more trustworthy 


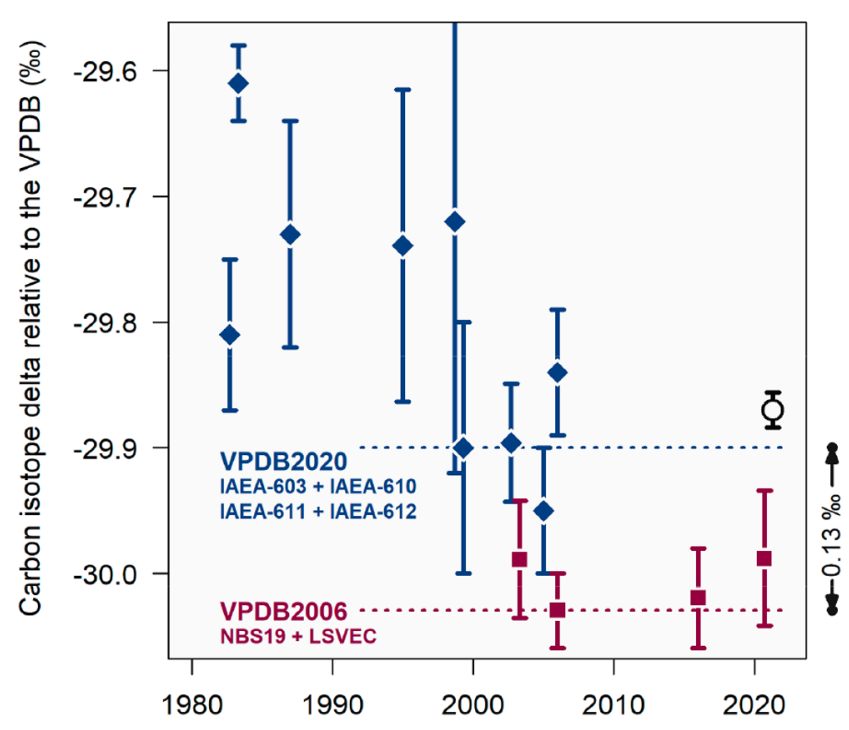

Measurements of NBS22 reference oil

Figure 2. Historic overview of carbon isotope delta measurements for the NBS22 reference oil ${ }^{2,6,10,14-21}$ shows the magnitude of errors inherent in realizing the VPDB scale, whether specifying a single (NBS19, solid diamonds) or two fixed points (NBS19 + LSVEC, solid squares). The black hollow circle is our measurement result obtained using IAEA 603-610-611-612 reference materials (the VPDB2020 scale realization). Error bars represent standard uncertainties.

measurements ${ }^{22}$ and bring the carbon isotope measurement science within the reach of the 0.01-0.02\%o WMO data quality targets.

\section{ASSOCIATED CONTENT}

\section{SI Supporting Information}

The Supporting Information is available free of charge at https://pubs.acs.org/doi/10.1021/acs.analchem.1c02458.

Materials and methods with a description of the combustion efficiency assessment and statistical analysis method (PDF)

Excel file containing all raw data measured during this study with calculated uncertainties, Table $1, \mathrm{R}$ code used to produce Figure 1 and Table 1 , and data used to produce Figure 2 (XLSX)

\section{AUTHOR INFORMATION}

\section{Corresponding Author}

Jean-François Hélie - Département des sciences de la Terre et de l'atmosphère, Université du Québec à Montréal, Montréal QC H3C 3P8, Canada; Geotop Research Centre on the Dynamics of the Earth System, Montréal QC H3C 3P8, Canada; 이이.orcid/0000-0002-0994-5620; Email: helie.jean-francois@uqam.ca

\section{Authors}

Agnieszka Adamowicz-Walczak - Geotop Research Centre on the Dynamics of the Earth System, Montréal QC H3C 3P8, Canada

Paul Middlestead - University of Ottawa, Earth and Environmental Sciences Department, Ottawa ON K1N 6N5, Canada
Michelle M.G. Chartrand - National Research Council Canada, Metrology, Ottawa ON K1A 0R6, Canada; (1) orcid.org/0000-0003-3398-7246

Zoltán Mester - National Research Council Canada, Metrology, Ottawa ON K1A 0R6, Canada; ㅇo이.org/ 0000-0002-2377-2615

Juris Meija - National Research Council Canada, Metrology,

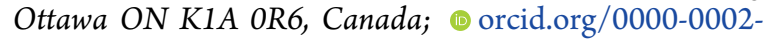
3349-5535

Complete contact information is available at:

https://pubs.acs.org/10.1021/acs.analchem.1c02458

\section{Author Contributions}

Conceptualization: J.F.H., P.M., M.M.G.C., Z.M., and J.M. Data curation: J.M. Formal analysis: J.M. Investigation: A.A.W. Methodology: J.F.H., M.M.G.C., Z.M., and J.M. Resources: J.F.H. Software: J.M. Validation: J.F.H. and A.A.W. Visualization: J.M. Writing-original draft: J.M. Writing: J.M., J.F.H., and Z.M.

\section{Notes}

The authors declare no competing financial interest.

\section{ACKNOWLEDGMENTS}

The stable isotopes laboratory of the Geotop research center is partly supported by the Fonds de recherche du QuébecNature et technologies (FRQNT), Grant No. 2018-RS203300.

\section{REFERENCES}

(1) Coplen, T. B. Pure Appl. Chem. 1994, 66, 273-276.

(2) Coplen, T. B.; Brand, W. A.; Gehre, M.; Gröning, M.; Meijer, H. A.; et al. Anal. Chem. 2006, 78, 2439-2441.

(3) Assonov, S. Rapid Commun. Mass Spectrom. 2018, 32, 827-830.

(4) Assonov, S.; Gröning, M.; Fajgelj, A.; Hélie, J.-F.; HillaireMarcel, C. Rapid Commun. Mass Spectrom. 2020, 34, e8867.

(5) Assonov, S.; Fajgelj, A.; Hélie, J.-F.; Allison, C.; Gröning, M. Rapid Commun. Mass Spectrom. 2021, 35, e9014.

(6) Qi, H.; Moossen, H.; Meijer, H. A. J.; Coplen, T. B.; AertsBijma, A. T.; et al. Rapid Commun. Mass Spectrom. 2021, 35, e9006.

(7) Fleisher, A. J.; Yi, H.; Srivastava, A.; Polyansky, O. L.; Zobov, N. F.; Hodges, J. T. Nat. Phys. 2021, DOI: 10.1038/s41567-021-01226-y.

(8) Malinovsky, D.; Dunn, P. J. H.; Holcombe, G.; Cowen, S.; Goenaga-Infante, H. J. Anal. At. Spectrom. 2019, 34, 147-159.

(9) Preston-Thomas, H. Metrologia 1990, 27, 3.

(10) Coplen, T. B.; Kendall, C.; Hopple, J. Nature 1983, 302, 236238.

(11) Meijer, H. A. J.; Neubert, R. E. M.; Visser, G. H. Int. J. Mass Spectrom. 2000, 198, 45-61.

(12) Assonov, S.; Fajgelj, A.; Allison, C.; Gröning, M. Rapid Commun. Mass Spectrom. 2021, 35, e9018.

(13) Chartrand, M. M. G.; Meija, J.; Kumkrong, P.; Mester, Z. Rapid Commun. Mass Spectrom. 2019, 33, 272-280.

(14) Hut, G. Consultant's group meeting on stable isotope reference samples for geochemical and hydrological investigations, IAEA, Vienna, 1987.

(15) Schoell, M.; Faber, E.; Coleman, M. L. Org. Geochem. 1983, 5, $3-6$.

(16) Gonfiantini, R. Reference and intercomparison materials for stable isotopes of light elements (IAEA-TECDOC-825, 1995).

(17) Wieser, M. E.; Brand, W. A. Rapid Commun. Mass Spectrom. 1999, 13, 1218-1225.

(18) Verkouteren, R. M. Anal. Chem. 1999, 71, 4740-4746.

(19) Qi, H.; Coplen, T. B.; Geilmann, H.; Brand, W. A.; Böhlke, J. K. Rapid Commun. Mass Spectrom. 2003, 17, 2483-2487. 
(20) Stalker, L.; Bryce, A. J.; Andrew, A. S. Org. Geochem. 2005, 36, 827-834.

(21) Schimmelmann, A.; Qi, H.; Coplen, T. B.; Brand, W. A.; Fong, J.; et al. Anal. Chem. 2016, 88, 4294-4302.

(22) Milton, M. J. T.; Possolo, A. Nat. Phys. 2020, 16, 117-119. 